\title{
Pandemia, necropolítica e o real do desamparo
}

\section{Pandemic, necropolitics and the real of abandonment}

\author{
Ilka Franco Ferrari*1 \\ Mônica Eulália da Silva Januzzi*2 \\ Andréa Máris Campos Guerra*3
}

\begin{abstract}
O texto aborda a realidade social assolada pelo real que a pandemia de COVID-19 instaurou, considerando de modo mais específico o contexto brasileiro. Seu desenvolvimento reflete sobre os efeitos subjetivos deste contexto, ponderando laços sociais que contam com a circulação da morte, somadas às leis imperiosas e impiedosas do discurso da ciência aliado ao discurso do capitalista e o mercado. A gestão precária da saúde pública, fundamentada numa lógica necropolítica constitui imaginariamente um outro inimigo, que vigora como política de Estado e reduplica o desamparo inerente à condição humana. A conclusão indica que este momento, propício para a pulsão de morte se desvelar, abre portas para transformações na politica e para o aparecimento da nobreza humana que vivifica os corpos diante de situações dramáticas, ainda que o real se mantenha no horizonte do mal-estar na civilização.
\end{abstract}

Palavras-chave: Necropolítica, pandemia, real, desamparo

*1 Pontifícia Universidade Católica de Minas Gerais - PUC-Minas (Belo Horizonte, MG, Brasil)

*2 Faculdade Pitágoras (Betim, MG, Brasil)

${ }^{* 3}$ Universidade Federal de Minas Gerais - UFMG (Belo Horizonte, MG, Brasil) 


\section{ARTIGOS}

As constantes transformações inerentes ao movimento próprio da ordem social, também ensina a psicanálise, repercutem nos modos de subjetivação, diferentemente do que pensam alguns. Mas o estudioso que se ocupa desse campo de conhecimento logo é advertido de que o sujeito - do inconsciente - e falasser sujeito como efeito do ato de fala - não se confundem com a subjetividade - enquanto processo histórico-social de subjetivação. $\mathrm{O}$ primeiro supõe a dimensão singular e a subjetividade é mutante, é epocal. Tal constatação, já presente na orientação clínica e política deixada por Freud, tem sido repetida à exaustão, talvez pelo fato de a realidade social atual buscar se equilibrar sobre a perda de valores até então ordenadores do laço social. Frente a isso, se impõe a incessante convocação de Lacan (1953/1998) de que "deve renunciar à prática da psicanálise todo analista que não conseguir alcançar em seu horizonte a subjetividade de sua época" (p. 322).

Nessa direção, a subjetividade da época atual conta com o enquadre que a pandemia pelo novo coronavírus convoca, testemunhando a irrupção de um real que coloca em questão a presença da vida e a possibilidade da morte. No contexto humano, como a clínica do cotidiano tem ensinado, há os que não sofrem com o confinamento que tem sido adotado como medida preventiva, a exemplo de alguns psicóticos que se apaziguaram, encontrando sentido ou justificativa para o autismo que lhes caracteriza. Há ainda aqueles que se tornaram mais produtivos. Mas há também os traumatizados, indignados, sofridos, assustados, atordoados diante da falta de sentido presente na intrusão deste real... E aqui é preciso colocar nessa conta a importante entrada em cena do desamparo, que é inerente à constituição de cada sujeito, somado àquele desamparo que advém da precarização da rede de saúde pública do país em que se habita.

No Brasil, conforme se escuta rotineiramente, há uma crise sanitária. Os serviços de saúde estão em situação de urgência. A crise política é incontestável, escancarando a impotência e 
impossibilidade de se achar solução para a realidade instalada, deixando ver o uso que se tem feito do que se batizou como guerra contra o vírus. E um dado não mente: com a pandemia apareceu a face selvagem do capitalismo imperante, que descuida do investimento em saúde pública, da prevenção e do cuidado, sobretudo, do cidadão mais necessitado, daquele que, em geral, é visto como descartável.

O contexto do atual governo brasileiro favorece reflexões acerca do viés necropolítico (Mbembe, 2020), no que tange à sua política pública em funcionamento, na qual os sujeitos são reduzidos a corpos matáveis, acirrando os processos de segregação das comunidades de gozo, já assinalados por Lacan. O remanejamento dos grupos sociais pela ciência, como agora experimentamos com a COVID-19 e seus grupos de maior risco, e o futuro de mercados comuns globalizados, com o ideal neoliberal impondo-se sobre a vida, encontrarão "seu equilíbrio numa ampliação cada vez mais dura dos processos de segregação" (Lacan, 2003/1967, p. 263). Desvela-se também, nesse cenário, a biopolítica que governa os corpos e os efeitos da relação com um Outro social que veicula a tirania, nos moldes da "Verleugnung", o desmentido freudiano (Ferrari, 2014). Vale a pena fazer algumas paradas em certos pontos aqui indicados.

\section{O real sem lei e a pandemia no horizonte de nossa época}

Não faz muito tempo, Miller (2012) anunciava o tema do IX Congresso da Associação Mundial de Psicanálise - AMP, convidando para uma reflexão sobre a prática psicanalítica, "seu contexto, suas condições, suas coordenadas inéditas no século XXI, quando cresce o que Freud chamava de 'Mal-estar na cultura', e que Lacan decifrava como os becos sem saída da civilização" (p. 1). Dois fatores são por ele destacados na medida em que reestruturam este contexto: o discurso da ciência e o do capitalismo.

É fato que tais ordenadores já se faziam presentes desde o início da Modernidade, produzindo profundos efeitos na subjetividade, implicando, fundamentalmente, as transformações da ordem simbólica. Os efeitos advindos de tal processo podem ser recolhidos na clínica a partir da desorientação dos corpos vista na errância, no isolamento, na ansiedade e suas formas de pânico, na inquietação, nos sintomas irruptivos presentes no acting out ou na passagem ao ato, e nas formas de desconexão social como a toxicomania e o suicídio (Miller, 2015a; Ferrari, 2008). É como se, no contemporâneo, o inconsciente se calasse e os corpos falassem. 


\section{ARTIGOS}

Laurent (2013) salienta que, na atual ordem social, as normas e suas inscrições não são suficientes para submeter os corpos a modos padronizados de inscrição no simbólico e, assim, o sintoma do sujeito denuncia os sintomas sociais da época. Sintoma social é modo de expressar aquilo que diz do que não vai bem, não funciona em determinada civilização. Para os propósitos deste texto, é útil mencionar, como exemplo, os entraves existentes para cumprimentos dos ideais democráticos e igualitários, regidos pela ordem simbólica, impedindo formas coletivas do tratamento do gozo, impossibilitando sua justiça distributiva para todos os cidadãos. Os brasileiros conhecem bem este sintoma social e suas envolturas formais na forma de segregação e violência.

Por outro lado, nesse mundo em que o registro simbólico se fragiliza, o Nome-do-Pai, foracluído, retorna no real, com a envoltura formal sintomática denominada, em certa época, por Lacan (1973-74), de "ordens de ferro", não deixando que o humano esqueça que nele habita a pulsão de morte. Essas ordens supõem leis implacáveis, totalitarismos de Estado, busca de mestres que restaurem a ordem perdida, na forma de pai severo, submetendo os corpos aos efeitos da lógica capitalista e suas leis de mercado, na solidão do mais de gozar. De acordo com Laurent (2013), "os corpos parecem ocupar-se deles mesmos. Se alguma coisa parece se apoderar deles, é a linguagem da biologia" (p. 1). E por esse caminho o discurso da ciência e do capital favorecem o enquadre no qual o cenário pandêmico atual se inscreve, produzindo os sintomas da época e os efeitos de real no sujeito.

No horizonte do século XXI pode-se então contar com a força do real, intensidade sem representação, que a psicanálise ensinou ser sem Lei, traumática, escapar ao sentido e trazer uma imprevisibilidade que faz falhar os cálculos. Enquanto a voracidade do mercado, ao contrário, se impõe com suas próprias leis. A esse respeito, Miller (2012) retoma Marx (1848), em "Manifesto do Partido Comunista", e o cita literalmente em dois trechos. A primeira citação é relativa ao fato de que "a burguesia só pode existir com a condição de revolucionar incessantemente os instrumentos de produção, por conseguinte, as relações de produção e, com isso, todas as relações sociais" (Marx, 1848, p. 3). E a segunda é para dizer que, nessas condições, "tudo que era sólido e estável se esfuma, tudo o que era sagrado é profanado" (p. 3).

$\mathrm{E}$, nesse contexto em que se situa a combinação binária entre ciência e capitalismo, se localiza a desorientação dos corpos própria do contemporâneo. Lógicas totalitárias, violência, segregação, racismo, depressões, compulsões, adicções e hipermedicalização são alguns dos meios pelos quais os sintomas 
de nossa época evidenciam essa desorientação. É, pois, sobre o laço social e sobre o corpo do ser falante que esse real sem lei e que escapa ao sentido demonstra seus efeitos intensificados em última instância. Nesse período de pandemia, em especial, testemunha-se a confrontação com a finitude, com os riscos que a fragilidade biológica impõe, com a privação da liberdade, com a vida que sai da norma habitual da produção e exige uma nova rotina com novas temporalidades, restritos deslocamentos e sociabilidades marcadas pela continuidade temporal do mundo virtual.

Trata-se, enfim, da disciplina dos corpos que não podem se contaminar. Tudo isso é radicalmente traumatizante. Sobretudo, considerando que aí se encontram modos de subjetivação que se valeram do individualismo ou mesmo do neoliberalismo modernos, marcados pela modulação do neo-sujeito eficaz, competitivo, destrutivo e empresa de si mesmo. Se o saber científico permite prever uma regularidade, como escreve Miller (2012), pode-se dizer que é justamente o que irrompe na realidade dessa nova regularidade que revela o real como desordem traumática. Ao vírus somam-se as leis imperiosas e impiedosas do mercado, senhor que regula o laço social e os corpos agenciados pela mais-valia como memorial de mais de gozo (Lacan, 1969-70/1992). Sua imposição desorienta e pressiona a proteção à vida, colocando em xeque seu valor.

Não se trata mais do pragmatismo de Bentham que otimiza os recursos em nome do maior prazer e da maior eficácia, como discutia Lacan nos anos 1960 (Lacan, 1959-60/1987), mas, de um modo de agenciamento que não faz laço social, ao colocar o sujeito numa relação direta com o objeto (Lacan, 1972). E quando, entre sujeito e objeto, o vírus se impõe em sua dimensão mortífera, sendo o Estado incapaz de fazer sua gestão e o mercado, encurralado, impossibilitado de usufruir de sua presença, o introduz na rotina neoliberal dos corpos, esse triste encontro traumatiza. "A ciência [porém] atravessa felizmente essa crise de responsabilidade" (Lacan, 1974, p. 3). E a psicanálise forja chaves de leitura, a partir de sua experiência clínica, para ler essa face do real.

\section{O Outro inimigo e a necropolítica}

Nesse tempo em que o discurso da ciência reina, aliado ao discurso do capitalista e à tecnologia, a humanidade se impactou quando, em março de 2020, a Organização Mundial de Saúde - OMS, oficializou o cenário de 


\section{ARTIGOS}

pandemia de COVID-19. Trata-se de um vírus mortífero, que parece gostar de mostrar os furos desses sistemas e que, com sua existência, tem forçado mudanças radicais nos modos de vida.

Não resultaram eficazes palavras e ações de governantes minimizando fatos e efeitos letais da pandemia, no intuito perverso de que a economia não pare. $\mathrm{O}$ vírus quer viver, não fala e parece estar cumprindo eficazmente sua condição de existir. Consequentemente, por trabalhar bem em nome de sua causa, mostra a inconsistência dos mestres que operam a maquinaria das cidades e lança luz sobre o que o discurso do mestre, desarticulado pelo discurso do capitalista, encobria.

No Brasil, as condições socioeconômicas e sociodemográficas têm pesado na estatística de pobres e negros mortos. As medidas de isolamento social, que não foram apoiadas pelo governo federal, quando enfatizadas pelos governos estaduais, evidenciaram que a geografia das desigualdades traria dificuldades ainda maiores para regiões periféricas enfrentarem a pandemia. Se a possibilidade de minimizar seus efeitos supõe a realização de medidas sanitárias de higiene, a falta de saneamento básico, água e sabão, é realidade comum em muitas casas, com muitos habitantes no mesmo espaço, assim como para aqueles que moram nas ruas. Nesses casos, a atuação de Organizações Não Governamentais (ONGs) tem sido fundamental, como tem sido ressaltado pela imprensa (Jornal Estado de Minas, 2020), a partir do know how que acumulam, com ações sociais coordenadas e geração de dados de populações em situação de vulnerabilidade. Não foi mais possível esconder essa população invisível, especialmente a partir do cadastro social que se implantou no país. Essa parte do ordenamento social, referida a milhares de pessoas que sequer acessam as políticas públicas, emergiu como contingente necessário e se tornou visível no plano público.

No âmbito da saúde pública, o país tem protagonizado uma política sanitária frágil, fragmentada e descoordenada. Ela rompe não apenas com princípios do SUS, tais como universalização, integralidade e equidade, como também com seus princípios organizativos de regionalização, hierarquização, descentralização e comando único e, sobretudo, com o controle social (Brasil, 1990). Cada Estado e cada município adotam medidas próprias, já que falta uma liderança capaz de unificar um plano de ação pautado no saber epidemiológico. Aqui, até mesmo as elucubrações do saber científico encontram dificuldades de se manterem frente ao discurso do capital e da religião, que orienta as ações do governo brasileiro. Chega-se ao cúmulo de a política de informações sofrer o crivo dos interesses narcisistas e partidários dos agentes governamentais. 
Nesse ponto, vale recordar que, se Lacan enfatizou que não há formas de vida sem discurso, como relembra Laurent (2019), porque eles "nos guiam, indicam como viver" (p. 39), há também aqueles discursos que nos fazem morrer, nos matam. São discursos que constroem o inimigo, proferidos "por agentes que se apresentam como grandes servidores do Estado, e até mesmo como heróis modernos sacrificando sua humanidade para cumprir seu dever" (p. 39), recorda Laurent. ${ }^{1}$ Eles estão por toda parte, disseminando ódio, segregação, racismos, decidindo eleições, construindo inimigos em nome do politicamente correto, proliferando vidas matáveis, hierarquizando o direito à vida.

No plano político, tornou-se familiar na atualidade, uma forma de populismo diferente da dos anos 1930. Ele surge da decadência das ideologias que vigoravam no século XX, ancoradas no marxismo e no racismo. Laurent (2019, p. 48), ao abordar o tema, cita o cientista político Raphël Liogier, que a situa originada da angústia coletiva diante da globalização, nela contando fatores de imigração desenfreada, capitalismo sem fronteira, islamização do mundo e o pós-ideológico. O que faz o "opinativo" e qualificado como "populismo líquido".

Se por um lado isto parece bom, porque retira o sujeito de certas fixidezes ideológicas, por outro o torna muito perigoso, porque "pode mudar de inimigos todos os dias", e constrói, portanto, um "banco central de ódio". Obtém-se, daí, um modo diferente do nacionalismo tribal. Nele não há o sentido do sacrifício, mas apelo ao gozo ilimitado, eliminando aqueles que não gozam do mesmo modo.

De acordo com essas considerações, na aula "La era del hombre de cantidad", Miller (2015b, p. 127) considera que os sentimentos de dominar e ser dominado não deixaram de existir. Segue existindo o mestre, mas este não é mais o Um, ainda que permaneça sua função de representante, por exemplo, nos presidentes eleitos. Ele considera que a humanidade está mais propensa a encarnar a dominação em um discurso, considerando a realidade social democrática em que "a ciência aloja certo 'todos iguais', particularmente manifesto na prática da eleição política: um homem, uma voz” (p. 129).

${ }^{1}$ Laurent retoma as palavras do psicanalista Gil Caroz, proferidas durante um Fórum Europeu com o título de "Os discursos que matam", ocorrido em setembro de 2018. 


\section{ARTIGOS}

Cenários como esses remetem um leitor atento às contribuições que o filósofo e pensador camaronês, Achille Mbembe (2016; 2020), trabalha como necropolítica, ou seja, práticas de exceção promovidas pelo Estado, e que subjugam, massacram e sacrificam certas populações em detrimento de outras em nome da soberania. Trata-se da expressão máxima de uma noção perversa de soberania, que dita quem deve viver e quem deve morrer, pois nela reside o que subjaz a todo o sistema que define aquele que deve ser o condenado, bem como os direitos do Estado sobre sua vida. "Minha preocupação é com aquelas formas de soberania cujo projeto central não é a luta pela autonomia, mas 'a instrumentalização generalizada da existência humana e a destruição material de corpos humanos e populações"' (Mbembe, 2020, p. 125).

A imprensa escrita e falada, nacional e internacional, por exemplo, não deixou de colocar à disposição do olhar e da escuta, a "licença para matar", dada à polícia do Rio de Janeiro, alinhando política estadual e federal. Vale lembrar que a política defendida pelo atual governo federal brasileiro, na contramão da tendência internacional, conta com o armamento da população, deixando subentendida a ideia de que uma arma nas mãos de certos grupos sociais é legal porque é preciso defender a propriedade privada, mas nas mãos das populações periféricas, é crime.

A necropolítica é um conceito oriundo da noção de biopolítica de Foucault (2002), que se articula como mudança de regime soberano que passa do fazer morrer, deixar viver para uma operação sobre populações no sentido de fazer viver e deixar morrer. Esse dispositivo volta-se ao controle estatístico das populações e dos corpos, em síntese, do controle da vida. Deste modo, "as disciplinas do corpo e as regulações da população constituem os dois pólos em torno dos quais se desenvolveu uma organização do poder sobre a vida" (Foucault, 2002, p. 131). E se impôs sobre o modo de poder disciplinar, que visava barrar, dobrar e destruir forças, baseado no direito de morte. Com a biopolítica, surge um poder destinado a regular a vida (Foucault, 2002, p. 128).

A outra face da necropolítica, desenvolvida mais recentemente por Mbembe (2020), é o direito de matar num regime de permanente ex- ceção. Ele articula com Arendt a ideia da solução final dos campos de concentração como "metáfora central para a violência soberana e destrutiva e como o último sinal do poder absoluto do negativo" (p. 7). Assim, a necropolítica de Mbembe evidencia um novo poder soberano que define os que podem viver e os que devem morrer. "Ser soberano é exercer controle sobre a mortalidade e definir a vida como a implantação e manifestação de poder" (Mbembe, 2016, 
p. 5). O autor toma a guerra como modelo de gestão e o racismo como base da construção do inimigo do Estado, legitimando corpos para a morte. Se esse é um elemento constitutivo do Estado Moderno, cujo paradigma é o terror do nazismo, a violência e a segregação da diferença são sua instrumentalidade.

É notável que a escravização e o sistema da plantation tenham sido o marco histórico desse novo modelo de Estado e de Economia que, com a experiência da pandemia, se tornou evidente e obsceno. "A vida do escravo, em muitos aspectos, é uma forma de morte-em-vida" (Mbembe, 2016, p. 29), denotando o marco inicial de uma necropolítica. O escravizado, desumanizado, é coisificado e transformado em mercadoria e propriedade de um senhor, Humano. "Ele é a figura perfeita de uma sombra personificada" (p. 30). Muito antes da tecnologia da morte dos campos de concentração ou daquela dos hospitais públicos de nosso século, agora tomados pela COVID-19, os navios negreiros encarnavam o valor de um corpo matável. Isso, enquanto as colônias davam corpo a um território de exceção, sem lei e habitado por selvagens primitivos e sem alma, sem qualquer relação racial evidente entre interesses do colonizador e violências contra o colonizado.

Hoje, claramente esse estado se atualiza. Infelizmente não é um passado 572 distante. Sem nos alongarmos em seus desdobramentos contemporâneos por todo o planeta, podemos dizer que se modificam as estratégias de colonização pelo Império: geográfica e ontológica, econômica e política, epistemologicamente. "Soberania significa ocupação" (Mbembe, 2016, p. 39) e, podemos acrescentar, eliminação. Necropolítica é seu nome contemporâneo e, no Brasil de hoje, a lógica do poder soberano encarnado na gestão pública do país.

Vale ainda enfatizar, na constatação da gestão necropolítica no Brasil, a negligência com a cultura dos povos indígenas e, recentemente, os vetos de diversas medidas destinadas à saúde desses cidadãos, e também dos quilombolas, no combate à pandemia de COVID-19. Um deles consistia na liberação de leitos de Unidades de Tratamento Intensivo (UTI), para essas populações. Por outro lado, manteve-se a autorização de missões religiosas — fonte de contaminação dessas populações muitas vezes sem acesso a tratamento — nas aldeias. Os vetos foram justificados em função das medidas aumentarem a despesa pública. Em uma política que exerce o direito de matar, o que a necropolítica denuncia é que, neste regime, nem todas as vidas importam.

Há, no entanto, quem ainda manifesta a indignação, importante afeto para a vida civilizada, a exemplo dos autores anteriormente citados. O psicanalista Osvaldo Delgado tem seu modo de expressá-la, ao dizer que os psicanalistas respeitam o sintoma do sujeito, na medida em que nele 


\section{ARTIGOS}

está implicado seus modos de gozo. Mas ressalta que, "o que não podemos respeitar é um gozo que viole os Direitos Humanos. Além do real sem lei da pandemia, temos o imperativo do gozo de certos governos" (Delgado, 2020, p. 1) que, na medida em que automatizam as formas de vida, balizam-se na face fascista do neoliberalismo.

A vulnerabilidade e o desamparo a que se encontram assujeitadas populações inteiras, desvelam que, a esse desgoverno imposto pelo real do vírus, soma-se uma governabilidade necropolítica dos corpos. Como pensar essa nova vulnerabilidade que envolve a incidência do real no Estado, no Capital e na Ciência na perspectiva psicanalítica? A noção de desamparo pode nos servir de guia para uma possível resposta.

\section{Desamparados}

O leitor de Freud, e que conhece Lacan, percebe que sua formalização acerca do desamparo comporta o real traumático, que escapa à inscrição simbólica: "Denominemos uma situação de desamparo, [...] de situação traumática" (Freud, 1926/1960c, p. 161). A dimensão traumática do desamparo surge, na clínica freudiana, com as neuroses de guerra. $\mathrm{O}$ trauma, neste trabalho de Freud (1920/1996f), consiste numa ruptura na barreira de proteção do aparelho psíquico, em função de uma ameaça inesperada àquilo que mantém as exigências da a. E, aqui, cabe dizer que, para os seres falantes as ameaças às exigências da vida consistem em perigos pulsionais.

Nesse sentido, não é por acaso que Freud (1920/1996f) propõe esta teorização do trauma balizando-a em sua segunda dualidade pulsional: a pulsão de vida e a pulsão de morte. O princípio do prazer, princípio que rege as relações com a vida e com o laço social, perde funcionalidade e, na medida em que o psiquismo curto-circuita em sua economia pulsional, a pulsão de morte se instaura. E a angústia, como ele escreve anos mais tarde, surge sinalizando para o perigo em causa, diante da ameaça à vida, não mais simbolizável (Freud, 1926/1960c). Ela força o psiquismo a produzir sintomas capazes de oferecer algum arranjo para o que está sem lei, sem sentido, sem representação.

A partir de Freud, a noção de desamparo tem sido objeto de estudo de diversos autores. Januzzi (2018) a trabalha a partir de três modalidades - desamparo estrutural, desamparo radical e desamparo generalizado -, extraídas do estudo com adolescentes em situação de vulnerabilidade e em 
dificuldades com a dimensão do desejo. A primeira modalidade, proposta por Januzzi (2018), é a do desamparo estrutural.

No campo constitutivo do sujeito do gozo e da linguagem, o desamparo é parte fundamental dessa operação lógica de constituição subjetiva. Diante do desamparo primordial do pequeno vivente, como escreve Freud (1895/1996a), uma alteridade, com sua ação específica, apazigua o estado de tensão, inaugurando um tempo ainda remoto da relação de objeto. Aqui o texto freudiano "Projeto para uma psicologia científica" é a principal baliza, embora esse modo de desamparo também apareça ao longo de toda sua obra, mantendo uma regularidade que permitirá designá-la, também, como um estado de desamparo infantil (Freud, 1905/1996b; 1927/1996d; 1930/1996e).

Tízio (2006) reafirma essa noção quando, no posfácio do livro de August Aichhorn, Juventude desamparada, retoma o significante "desamparo" para reafirmá-lo como algo que não se refere apenas à proteção contra perigos externos, mas também aos perigos internos, pulsionais, nos quais a função exercida pelo adulto incide. Para a psicanálise, é na relação com o Outro que necessidade, demanda e desejo, engendram a trama que constitui o sujeito e o inscreve na linguagem. É nessa operação lógica que um organismo vivo 574 ultrapassa a dimensão puramente biológica, ou seja, de um corpo puramente biológico, para se constituir em um sujeito.

A dimensão generalizada do desamparo é a segunda modalidade. Como não falar aqui, como ressalta Sotelo (2020, p. 1), do desamparo que implica o fato de que, no capitalismo selvagem, só se promove saúde para quem pode pagar por ela? No Brasil, o Sistema Único de Saúde resiste a essa lógica, mas não pode deixar de ser impactado pela falta de investimento e pela inversão de sua lógica que o governo atual lhe impõe. A fragilidade nos sistemas de cuidado, prevenção e proteção, bem como a insuficiência dos recursos de urgência, assinalam a dimensão generalizada do desamparo que se mostra, por exemplo, no pânico de não se ter o direito a ser amparado.

Aqui, a noção de Outro que não existe, estabelecida por Miller (2010), é o paradigma que permite pensar as transformações da ordem social da época e os efeitos do real que se impõem na subjetividade do sujeito. O Outro, tomado como tela ficcional para o real, aparato simbólico que resguarda o campo dos significantes, pode ser materializado por diferentes formas de alteridade. As transformações de nossa época respondem a um contexto de denegação em que, frente ao desamparo do Outro social e político, o sujeito, no tecido social, se reduz a um corpo-objeto, passível de controle necropolítico, útil apenas enquanto movimenta a máquina econômica. 
A esse respeito, Delgado (2020, p. 1) propõe uma criteriosa discussão sobre os efeitos ideológicos, presentes na ordem social atual, sobretudo daquelas que desconhecem a existência do outro, o semelhante concreto. Ele recorda que a compulsão à repetição, que ordena o sintoma subjetivo, leva ao pior e pode se articular como ideologia, expressando-se como ódio no sentido aristotélico, afeto que conta com o movimento para que o outro não exista.

Assim, pode-se afirmar que a denegação dos valores civilizatórios, como fator político, favorece cenários que ilustram o que aqui se define como desamparo generalizado. Esses cenários, no contexto da pandemia, também se apresentam nas demissões em massa de trabalhadores ou na exposição de muitos outros aos riscos de contaminação de si mesmos e de seus familiares. $\mathrm{O}$ adoecimento psíquico que daí resulta também se manifesta nas equipes de saúde e nos afastamentos dos postos de trabalho (Delgado, 2020; Sotelo, 2020).

Em tempos em que as verdades são passíveis de desconstrução e o semblante ficcional do Outro da ética social se destitui, o sujeito denuncia os efeitos de seu desamparo generalizado. Mas, quando o desamparo estrutural fracassa em sua funcionalidade constitutiva, e quando o desamparo generalizado se intensifica, a ponto de levar o sujeito a prescindir do Outro, já que não há o que dele esperar, uma dimensão radicalmente desamparadora se instaura. Assim, na terceira modalidade do desamparo, Januzzi (2018) isolou como desamparo radical, na condição de que aí a ação da pulsão de morte como efeito do trauma se faz ainda mais avassaladora. O trauma aqui é o de não ter lugar no campo do Outro, não encontrar aí um re-conhecimento de sua condição de sujeito que importa no tecido social.

Como escreve Miller (2010), é no campo do Outro que o sujeito busca o objeto da satisfação de seu desejo, ainda que se depare com a frustração de jamais encontrá-lo. É também aí que se situa a relação de dependência do sujeito ao Outro, pois o desejo do sujeito está conformado à demanda do Outro. Por isso é devastador quando o Outro social demanda dos sujeitos o sacrifício de seus corpos.

Tais reflexões acerca do real da pandemia e seus efeitos de angústia, sempre singulares, encontram eco no mal-estar inerente à civilização, tal qual antevisto por Freud (1930/1996e) em sua dimensão de desamparo. Causa mal-estar o poder superior da natureza, a fragilidade dos corpos e "a inadequação das regras que procuram ajustar os relacionamentos mútuos dos seres humanos na família, no Estado e na sociedade" (p. 93). Nesse sentido, face ao desamparo estrutural, Freud antepõe a ação específica que implica 
o outro em sua função humanizadora no sentido de contornar o corpo e as primeiras experiências infantis com a linguagem e o cuidado. $\mathrm{O}$ que nos indica um caminho, transposta sua lógica ao momento atual, de se tomar as únicas medidas realmente eficazes contra o vírus desconhecido e fatal.

Essas medidas são aquelas que convocam o indivíduo ao pacto civilizatório, no caso, aquele que responde pelas medidas de isolamento social. Mas o pacto social falha quando os ordenadores da época funcionam sob lógicas perversas. Daí a necessária ação de cuidado para que o mal-estar não se generalize, atualizando-se na civilização, e para que o sujeito não pereça, sem ao menos receber a mínima proteção necessária.

Para Bassols (2020), o sujeito se angustia diante da natureza desordenada do real que não volta mais ao mesmo lugar, enquanto o "cientificismo promete superar a angústia com o saber, um saber que estaria inscrito no real desde o início. Em vão. A religião promete superá-la com o sentido. Em vão também" (p. 2). Ainda que as leis da natureza permitam à ciência prever suas ações e produzir elucubrações de saber sobre o real, a pandemia de COVID-19 responde a um real que é sem lei. O real da pandemia se estabelece na relação com o tempo, com o espaço, com o coletivo, com o corpo e na dimensão da própria condição de sujeito da fala e do gozo. Delgado (2020), leitor criterioso do texto freudiano, afirma que, para Freud, uma sociedade mais justa, econômica e socialmente, é aquela que oferece um tratamento para a pulsão de morte — daí a necessária ação de cuidado em nossa época.

\section{Apontamentos finais}

Em meio a este problema da pandemia como um real que se impõe, pode-se constatar, portanto, de forma perturbadora, a prevalência da pulsão de morte e da dimensão do desmentido. Ao localizar o foco no que tem acontecido no Brasil, ele ilumina a gestão necropolítica dos corpos matáveis desvelada pela COVID-19, que aparece até mesmo em perguntas com aparência de naturalidade, como por exemplo: "uns vão morrer mesmo! E daí?”. A aliança entre Ciência e Capital se descortina e interroga o valor da vida e a lógica atual do laço social. No cenário aparece, portanto, a figura central do desamparo que assola a todos, para alguns vivido de forma radical, exigindo que os sujeitos/cidadãos exercitem seus recursos na direção de um saber fazer com o inominável. 
E, assim sendo, nesse exercício também se pode iluminar oportunidades de transformações no contexto caótico que mostra sua face, tendo no horizonte a possibilidade de retificação política e do desalojamento do discurso capitalista, gerador de proletariado generalizado. Lacan, a partir de Max Weber, advertia que, nessa forma de laço social, na verdade todos são proletários. Por alguns cantos já ecoam vozes ao estilo de Étienne de La Boétie (2009): indignai-vos!

Nessa realidade social pobre de mestres encarnados no significante mestre que lhes favoreça uma essência distinta dos demais, fica difícil a preocupação com a heterogeneidade do mundo e proliferam-se os semblantes de igualdade. Mas, diante do discurso de morte despudorado, abrem-se portas para repensar a questão do Estado, do Estado de direito e dos modos singulares de funcionamento dos sujeitos.

$\mathrm{O}$ vírus, até o momento, parece ser antisegregativo. O humano cada vez mais exercita sua habilidade para segregar, namorar a pulsão de morte. Mas desde Freud se sabe que nele também há recursos nobres e, como ressalta Ventura (2020), eles curiosamente vivificam os corpos, quando se coloca em ato, a autenticidade da relação com coisas que importam, a exemplo da vida e da morte. Considerar a existência da pulsão de morte, nesse horizonte, é condição para que se possa também dar espaço a Eros, que não prescinde do Outro. E, na medida em que o Outro é sempre uma ficção, sempre haverá possibilidade de construção de algum semblante civilizatório.

\section{Referências}

Bassols, M. (2020, 26 mar.). Coronavírus: a lei da natureza e o real sem lei. Correio Expresses - Revista Eletrônica da Escola Brasileira de Psicanálise. Recuperado de: <https://www.ebp.org.br/correio_express/2020/03/26/a-lei-da-natureza-e-oreal-sem-lei/>.

Brasil (1990). Lei 8080 de 19 de setembro de 1990 - Lei Orgânica da Saúde. Ministério da Saúde. Dispõe sobre as condições para a promoção, proteção e recuperação da saúde, a organização e o funcionamento dos serviços correspondentes e dá outras providências. Recuperado de: $<$ http://www.planalto. gov.br/ccivil_03/leis/18080.htm>.

Delgado, O. (2020, 14 de abril). A renegação como fator político. Crônicas XXI - 24. Buenos Aires: Gramma. Recuperado de: <https://vo.mydplr.com/ a64e48a953446416bf0c777e498b9727-ce69bbe059e210a717920dbe62401ad5>. 
Ferrari, I. F. (2008). A realidade social e os sujeitos solitários. Ágora: Estudos em Teoria Psicanalítica, 11(1), 17-30. Recuperado de: <https://doi.org/10.1590/ S1516-14982008000100002>.

Ferrari, I. F. (2014). O consumidor e a perversão. Revista Latinoamericana de Psicopatologia Fundamental, 17(3), 652-665. Recuperado de: <https:// www.scielo.br/scielo.php?pid=S1415-47142014000600652\&script $=$ sci abstract\&tlng $=\mathrm{pt}>$.

Ferrari, I. F. (2018). Adolescentes usuários de drogas: o que ensinam ao tratamento que se realiza nos CAPSi. Tese de Doutorado, Programa de Pós-Graduação em Psicologia, PUC-Minas, Belo Horizonte.

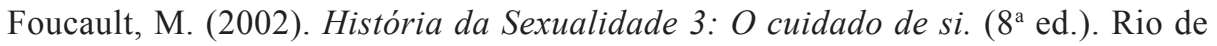
Janeiro, RJ: Graal.

Freud, S. (1996a). Projeto para uma psicologia científica. In Edição Standard Brasileira das Obras Psicológicas Completas de Sigmund Freud (vol. 1, pp. 335 -443). Rio de Janeiro, RJ: Imago. (Originalmente publicado em 1895).

Freud, S. (1996b). Os chistes e suas relações com o inconsciente. In Edição Standard Brasileira das Obras Psicológicas Completas de Sigmund Freud. (vol. 8, pp. 17-23). Rio de Janeiro, RJ: Imago. (Originalmente publicado em 1905).

Freud, S. (1996c). Inibições, sintomas e angústia. In Edição Standard Brasileira das Obras Psicológicas Completas de Sigmund Freud (vol.20, pp. 91-167). Rio de Janeiro, RJ: Imago. (Originalmente publicado em 1926).

Freud, S. (1996d). O futuro de uma ilusão. In Edição Standard Brasileira das Obras Psicológicas Completas de Sigmund Freud (vol. 21, pp. 15-63). Rio de Janeiro, RJ: Imago. (Originalmente publicado em 1927).

Freud, S. (1996e). Mal-estar na civilização. In Edição Standard Brasileira das Obras Psicológicas Completas de Sigmund Freud (vol. 21, pp. 67-148). Rio de Janeiro, RJ: Imago. (Originalmente publicado em 1930).

Freud, S. (1996f). Além do princípio do prazer. In Edição Standard Brasileira das Obras Psicológicas Completas de Sigmund Freud (vol. 18, pp. 13-75). Rio de Janeiro, RJ: Imago. (Originalmente publicado em 1920).

Januzzi (2018). Adolescentes usuários de drogas: dificuldades de adesão ao tratamento nos CAPSi. Tese de Doutorado, Programa de Pós-Graduação em Psicologia. Pontifícia Universidade Católica de Minas Gerais - PUC-Minas, Belo Horizonte.

La Boétie, E. (2009). Discurso da servidão voluntária. (Tradução de Casemiro Linarth). São Paulo, SP: Martin Claret.

Lacan, J. (1966-67). O seminário. Livro 14. A lógica da fantasia. Inédito. Recuperado de: <http://lacanempdf.blogspot.com/2018/04/seminario-14-logica-do-fantasmajacques.html $>$. 


\section{ARTIGOS}

Lacan, J. (1972). Du discours psychanalytique. Conférence à l'université de Milan. Recuperado de: $<$ http://pagesperso-orange.fr/espace.freud/topos/psycha/psysem/ italie.htm>.

Lacan, J. (1973-74). O seminário. Livro 21. Les non-dupes errent. Inédito.

Lacan, J. (1974). Entrevista inédita de Jacques Lacan a Emílio Granzotto para a Revista Panorama. Magazine Litéraire, 428, fev. 2004. Recuperado de: <https:// subversos.com.br/textos-ensaios-e-entrevistas-entrevista-inedita-de-jacques-lacana-revista-italiana-panorama-1974/>.

Lacan, J. (1987). O seminário livro 7. A ética da psicanálise. Rio de Janeiro, RJ: Jorge Zahar. (Trabalho original publicado em 1959-60).

Lacan, J. (1992). O seminário. Livro 17. O avesso da psicanálise. Rio de Janeiro, RJ: Jorge Zahar. (Trabalho original em 1969/70).

Lacan, J. (1998). Função e campo da fala e da linguagem. In Escritos. (pp. 238-324). Rio de Janeiro, RJ: Jorge Zahar. (Trabalho original publicado em 1953).

Lacan, J. (2003). Proposição de 9 de outubro de 1967 sobre o psicanalista da escola. In Outros escritos (pp. 248-264). Rio de Janeiro, RJ: Jorge Zahar. (Trabalho original publicado em 1967).

Laurent, E. (2013). Falar com seu sintoma, falar com seu corpo. VI Encontro Americano de Psicanálise da Orientação Lacaniana ENAPOL - XVIII Encontro Internacional do Campo Lacaniano. Buenos Aires: novembro. Recuperado de: $<$ http://www.enapol.com/pt/template.php?file=Argumento/Hablar-con-el-propiosintoma_Eric-Laurent.html>.

Laurent, E. (2019, out). Discursos e gozos maus. Correio 82.

Marx, K., \& Engels, F. (2020). Manifesto do partido comunista. (pp. 1-21). Domínio Público. Recuperado de: <http://www.dominiopublico.gov.br/download/texto/ cv000042.pdf $>$. (Trabalho originalmente publicado em 1848).

Mbembe, A. (2016). Necropolítica: biopoder, soberania, estado de exceção, política da morte. São Paulo, SP: n-1 edições.

Mbembe, A. (2020). O direito universal à respiração. São Paulo, SP: n-1 edições.

Mendonça, A. (2020, 27 de jul.). Coronavírus: ONGs ajudam moradores de rua durante a pandemia. Jornal Estado de Minas. Recuperado de: $<$ https://www. em.com.br/app/noticia/gerais/2020/05/19/interna_gerais,1148709/coronavirusongs-ajudam-moradores-em-situacao-de-rua-durante-pandemia.shtml $>$.

Miller, J.-A. (2010). El Otro que no existe y sus comités de ética. Buenos Aires, ARG: Paidós.

Miller, J-A. (2012). O real no século XXI - Apresentação do tema do IX ${ }^{\circ}$ Congresso da AMP. Associação Mundial de Psicanálise.

Miller, J-A. (2015a). Em direção à adolescência. Intervenção de encerramento da $3^{\mathrm{a}}$ 
Jornada do Instituto da Criança. 10 de junho de 2015. Recuperado de: <http:// minascomlacan.com.br/blog/em-direcao-a-adolescencia/> .

Miller, J-A. (2015b) La era del hombre de cantidad. In: Miller: J-A. Todo el mundo es loco. (pp. 127-142). Buenos Aires: Paidós.

Sotelo. I. (2020, 16 de abril). Instituiciones y discursos en tempos de coronavírus. Crônicas XXI - 26. Buenos Aires: Gramma. https://vo.mydplr.com/506d1eea99d 55ec4ad58caa90c2b5c0f-ce69bbe059e210a717920dbe62401ad5

Tízio, H. (2006). Prólogo. In Aichchorn, A. Juventud desamparada (pp. 9-20). Barcelona, ESP: Getisa Editorial.

Ventura, O. (2020, 14 de abril). La sombra de una sociedad policial aún se cierne sobre el futuro. In Crônicas XXI - Edição Especial AG. Buenos Aires, AR: Gramma, 14 de abril de 2020. Recuperado de <https://vo.mydplr. com/8bd72eaeb19a625936dd61a1257a7278-ce69bbe059e210a717920dbe6240 $1 \mathrm{ad} 5>$.

\section{Resumos}

(Pandemic, necropolitics and the real of abandonment)

This article addresses the social reality plagued by the real created by the COVID-19 pandemic in the Brazilian context. We reflect on the subjective effects of this context by taking into account the social bonds that rely on the circulation of death, added to the imperious and merciless laws of the scientific discourse, combined with the capitalist and market discourse. Poor public health management based on a necropolitical logic constitutes, in an imaginary way, another enemy, which prevails as a State policy and replicates the abandonment inherent to the human condition. We conclude that this moment, propitious for the death drive to unveil itself, opens doors for changes in politics and for the emergence of the noble-mindedness that enlivens bodies in the face of dramatic situations, despite the fact that the real remains on the horizon of the malaise of civilization.

Key words: Necropolitics, pandemic, real, abandonment

(Pandémie, nécropolitique et le réel du délaissement)

Cet article analyse la réalité sociale en proie au réel établi par la pandémie de COVID-19 dans le contexte brésilien. Nous développons une réflexion sur les effets subjectifs de ce contexte en prenant comptes des liens sociaux fondés sur la circulation de la mort, ajoutés aux lois impérieuses et impitoyables du discours scientifique, combiné au discours capitaliste et du marché. La gestion précaire de 


\section{ARTIGOS}

la santé publique, fondée sur une logique nécropolitique, constitue, de manière imaginaire, un autre ennemi, qui prévaut en tant que politique d'État et qui réplique le délaissement inhérent à la condition humaine. Notre conclusion indique que ce moment, propice au dévoilement de la pulsion de mort, ouvre les portes aux changements dans la politique et à l'émergence de la noblesse d'esprit qui anime les corps face à des situations dramatiques, malgré le fait que le réel reste à l'horizon du malaise de la civilisation.

Mots clés: Nécropolitique, pandémie, réel, délaissement

(Pandemia, necropolítica y lo real del desamparo)

Considerando de manera más especifica el contexto brasileño, el texto aborda la situación social arrasada por la realidad establecida por la pandemia de COVID-19. Se desarrolla una reflexión sobre los efectos subjetivos de este contexto, considerando los lazos sociales que cuentan con la circulación de la muerte, sumados a las leyes imperiosas y despiadadas del discurso científico, asociados al discurso capitalista y del mercado. La precaria gestión de la salud pública, basada en una lógica necropolítica, constituye de manera imaginaria otro enemigo que prevalece como política de Estado y que reduplica el desamparo inherente a la condición humana. La conclusión indica que este momento, propicio para que la pulsión de muerte se desvele, abre las puertas para cambios en la política y para el surgimiento de la nobleza humana, que aviva los cuerpos ante situaciones dramáticas, aunque lo real permanezca en el horizonte del malestar de la civilización.

Palabras clave: Necropolítica, pandemia, real, desamparo

Citação/Citation: Ferrari, I. F., Januzzi, M. E. da S., \& Guerra, A. M. C. (2020, setembro). Pandemia, necropolítica e o real do desamparo. Revista Latinoamericana de Psicopatologia Fundamental, 23(3), 564-582. http://dx.doi.org/10.1590/1415-4714.2020v23n3p564.8.

Editora/Editor: Profa. Dra. Ana Maria G. R. Oda e Profa. Dra. Sonia Leite

Submetido/Submitted: 13.8.2020 / 8.13.2020 Aceito/Acepted: 18.8.2020 / 8.18.2020

Copyright: (C) 2009 Associação Universitária de Pesquisa em Psicopatologia Fundamental/ University Association for Research in Fundamental Psychopathology. Este é um artigo de livre acesso, que permite uso irrestrito, distribuição e reprodução em qualquer meio, desde que o autor e a fonte sejam citados / This is an open-access article, which permits unrestricted use, distribution, and reproduction in any medium, provided the original authors and sources are credited. 
Financiamento/Funding: Este trabalho não recebeu apoio / This work received no funding..

Conflito de interesses/Conflict of interest: As autoras declaram que não há conflito de interesses. / The authors declare that there is no conflict of interest.

\section{ILKa Franco Ferrari}

Pós-Doutora pela Universidade de Barcelona (Barcelona, Espanha); Doutora em Psicologia pelo Programa de Clínica y Aplicaciones del Psicoanális na Universidade de Barcelona (Barcelona, Espanha); Professora da PUC-Minas (Belo Horizonte, MG, Br) nos cursos de Graduação e Pós-graduação.

Rua Prof. José Renault, 526 - São Bento

30350-760 Belo Horizonte, MG, Br

ilkafferrari@gmail.com

http://orcid.org/0000-0002-6367-3136

\section{Mônica Eulália da Silva Januzzi}

Pós-doutoranda pela Universidade Federal de Minas Gerais - UFMG (Belo Horizonte, MG, Br); Doutora pela PUC-Minas (Belo Horizonte, MG, Br); Professora na Faculdade Pitágoras (Betim, MG, Br)

Rua José Borges Flores, 135 - Vila Triângulo, 32671-276 Betim, MG, Br monicaesilva@yahoo.com.br https://orcid.org/0000-0003-0788-9968

\section{Andréa Máris Campos Guerra}

Pós-Doutoranda na Université Paris 8 (Paris, França); Doutora em Teoria Psicanalítica pela Universidade Federal do Rio de Janeiro - UFRJ (Rio de Janeiro, RJ, Br); Professora adjunta do Departamento e do Programa de Pós-Graduação em Psicologia da Universidade Federal de Minas Gerais - UFMG (Belo Horizonte, MG, Br).

Rua Mares de Montanhas, 1325 - Vale dos Cristais 34008-056 Nova Lima, MG, Br andreamcguerra@gmail.com https://orcid.org/0000-0001-5327-0694

This is an open-access article, which permits unrestricted use, distribution, and reproduction in any medium for non-commercial purposes provided the original authors and sources are credited. 